Case Report

\title{
Role of Leading Programs in Doctoral Education: A New Type of Leadership Education in the Sciences at University of Hyogo, Japan
}

\section{Maya Okamoto ${ }^{1, *}$ and Hiroshi Matsuzaka ${ }^{2}$}

1 Office for Leading Program in Doctoral Education, Graduate School of Life Science, University of Hyogo, Koto 3-2-1, Kamigori-cho, Ako-gun, Hyogo 678-1297, Japan

2 Ministry of Education, Culture, Sports, Science and Technology, Japan (MEXT), Kasumigaseki 3-2-2, Chiyoda-ku, Tokyo 100-8959, Japan; E-Mail: matsu@mext.go.jp

* Author to whom correspondence should be addressed; E-Mail: myok@sci.u-hyogo.ac.jp; Tel.: +81-791-58-0101 (ext. 0183); Fax: +81-791-58-0131.

Academic Editor: John Blewitt

Received: 4 November 2014 / Accepted: 6 January 2015 / Published: 12 January 2015

\begin{abstract}
Fostering global leaders for the next generation is an important mission of universities. In Japan, Leading Programs in Doctoral Education (LP) has been implemented in many graduate schools. The main goal of this program is to foster PhDs with deep specialization and peer leadership who will be able to compete well internationally. The Graduate School of Life Science, University of Hyogo is implementing a LP to foster global leaders using cutting-edge technology. They are also trying to create new evaluation criteria of human resource development with their corporate sponsors. The success of LP depends not only on how many graduates can play leading roles globally, but also how university staff can create a superior new evaluation criteria of human resource development and how much it can be shared with universities and industry. Development of students and graduates with a high level of ability takes time, thus it is important to consider the continuous development of LP.
\end{abstract}

Keywords: leading program (LP); doctoral education; leadership; science education; evaluation criteria 


\section{Introduction}

Universities are faced with the challenge of educating students to become global leaders for the next generation. Many programs have been implemented in various fields to foster global leaders all over the world [1-4]. However, most of them have either been academically specialized or comprised only of vocational training such as laboratory based technical training. These programs have indeed produced many academic researchers and trained workers, but have not generated "global leaders" who could play leading roles in industrial and governmental sectors. In this study, we discuss a new type of leadership education and create its evaluation criteria by introducing the case of science and leadership education at University of Hyogo.

The Leading Programs in Doctoral Education (LP) was started by the Ministry of Education, Culture, Sports, Science and Technology, Japan (MEXT) in 2011 to advance the establishment of university graduate schools of the highest caliber by supporting dramatic reform of their education curricula so that their degree programs will be recognized as of top quality around the world [5]. To foster excellent students who are both highly creative and internationally attuned and who will play leading roles in global academic, industrial, and governmental sectors, the program brings top-ranking faculty and students together from both within and outside Japan and enlists participation from other sectors in its planning and execution, while creating continuity between master and doctoral programs and implementing curricula that cross over various fields of specialization.

LP sounds very much like the US IGERT (Integrative Graduate Education and Research Traineeship) -the National Science Foundation's flagship interdisciplinary training program, educating PhD scientists and engineers by building on the foundations of their disciplinary knowledge with interdisciplinary training. Collaborative research that transcends traditional disciplinary boundaries and requires teamwork provides students with the tools to become leaders in the science and engineering of the future [6]. However, LP intended not only for science and engineering but also law and literature fields is a novel concept.

LP is divided into three categories: all-around, composite, and only-one (Figure 1).

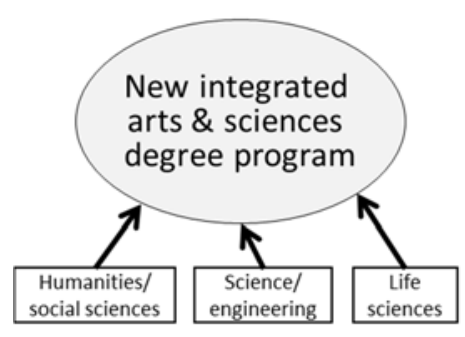

All-around category

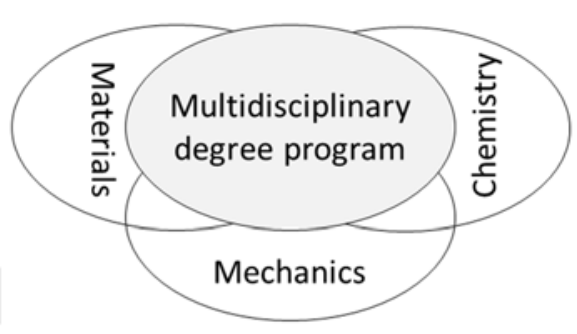

Composite category

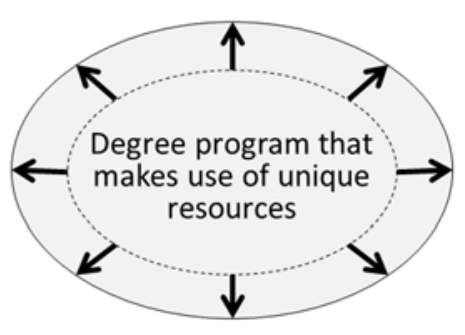

Only-one category

Figure 1. Categories of Leading Program in Doctoral Education (LP).

The all-around category involves constructing a degree program that uses an integrated arts and sciences model, and pools the university's collective wisdom to nurture future political, financial, administrative, and academic leaders who will become active in Japan and abroad, and lead global societies. The composite category entails a degree program that cuts across multiple fields to train leaders who can supervise industry—academia—government projects and who can drive innovation in 
solving the problems that society encounters. The only-one category comprises a degree program to develop leaders who would develop new fields utilizing the exceptional resources that are unique to Japan. By the end of March 2014, 62 programs had been adopted (Table 1).

Table 1. Sixty-two Leading Programs in Doctoral Education (LP) by the Ministry of Education, Culture, Sports, Science and Technology, Japan (MEXT).

\begin{tabular}{|c|c|c|}
\hline Categories & University & Program \\
\hline \multicolumn{3}{|l|}{ All-around category } \\
\hline & Kyoto University & Graduate school of advanced leadership studies, Kyoto University \\
\hline & Osaka University & Cross-boundary innovation program \\
\hline & The University of Tokyo & Global leader program for social design and management \\
\hline & Kyushu University & $\begin{array}{l}\text { Graduate education and research training program in decision science for } \\
\text { sustainable society }\end{array}$ \\
\hline & Keio University & Science for development of super mature society \\
\hline & Tokyo Institute of Technology & Academy for global leadership \\
\hline & Nagoya University & PhD professional: Gateway to success in frontier Asia \\
\hline \multicolumn{3}{|l|}{ Composite category } \\
\hline \multirow{6}{*}{ Environment } & The University of Tokyo & Graduate program in sustainability science: Global leadership initiative \\
\hline & Tokyo Institute of Technology & Academy for co-creative education of environment and energy science \\
\hline & Nagoya University & Integrative graduate education and research program in green natural sciences \\
\hline & Keio University & Global environmental system leaders program \\
\hline & $\begin{array}{l}\text { Tokyo University of } \\
\text { Agriculture and Technology }\end{array}$ & $\begin{array}{l}\text { Creation of the practical science leading graduate school for green and clean food } \\
\text { production }\end{array}$ \\
\hline & Kyushu University & Advanced graduate program in global strategy for green Asia \\
\hline \multirow{6}{*}{ Life sciences/health } & University of Tsukuba & Ph.D. program in human biology \\
\hline & The University of Tokyo & Graduate program for leaders in life innovation \\
\hline & Tokyo Institute of Technology & Education academy of computational life sciences \\
\hline & Osaka University & $\begin{array}{l}\text { Interdisciplinary graduate school program for systematic understanding of } \\
\text { health and disease }\end{array}$ \\
\hline & Kyoto University & $\begin{array}{l}\text { Training program of leaders for integrated medical system for fruitful } \\
\text { healthy-longevity society }\end{array}$ \\
\hline & Kumamoto University & HIGO: Health life science Interdisciplinary and glocal oriented \\
\hline \multirow{3}{*}{ Safety \& security } & Kyoto University & $\begin{array}{l}\text { Inter-graduate school program for sustainable development and } \\
\text { survivable societies }\end{array}$ \\
\hline & Tohoku University & Inter-graduate school doctoral degree program on science for global safety \\
\hline & University of Kochi & Disaster nursing global leader; DNGL \\
\hline \multirow{6}{*}{ Material } & The University of Tokyo & $\begin{array}{l}\text { Materials education program for the future leaders in research, industry, and technology } \\
\text { (MERIT) }\end{array}$ \\
\hline & Hokkaido University & Hokkaido university ambitious leader's program \\
\hline & Tohoku University & $\begin{array}{l}\text { Interdepartmental doctoral degree program for multi-dimensional materials science } \\
\text { leaders }\end{array}$ \\
\hline & $\begin{array}{l}\text { Osaka Prefecture University, } \\
\text { Osaka City University }\end{array}$ & Graduate Course for system-inspired leaders in material science \\
\hline & Osaka University & Interactive materials science cadet program \\
\hline & Kyushu University & Graduate school for molecular system \& device science \\
\hline
\end{tabular}


Table 1. Cont.

\begin{tabular}{|c|c|c|}
\hline Categories & University & Program \\
\hline \multirow{7}{*}{ Information } & The University of Tokyo & Graduate program for social ICT global creative leaders \\
\hline & Kyoto University & Collaborative graduate program in design \\
\hline & University of Tsukuba & Ph.D. program in empowerment informatics \\
\hline & Nagoya University & Graduate program for real-world data circulation leaders \\
\hline & $\begin{array}{l}\text { Toyohashi University } \\
\text { of Technology }\end{array}$ & Doctoral degree program for training brain information architects \\
\hline & Waseda University & Graduate Program for Embodiment Informatics \\
\hline & Osaka University & Humanware innovation program \\
\hline \multirow{6}{*}{$\begin{array}{l}\text { Symbiotic } \\
\text { multicultural society }\end{array}$} & Kanazawa University & Graduate program in cultural resource management \\
\hline & The University of Tokyo & Integrated human sciences program for cultural diversity \\
\hline & Nagoya University & Women leaders program to promote well-being in Asia \\
\hline & Hiroshima University & Taoyaka Program for creating a flexible, enduring, peaceful society \\
\hline & Osaka University & Doctoral program for multicultural innovation \\
\hline & Doshisha University & Global resource management \\
\hline \multirow{6}{*}{ Cross-cutting themes } & The University of Tokyo & Advanced graduate course for photon science \\
\hline & Hiroshima University & $\begin{array}{l}\text { Phoenix leader education program (Hiroshima Initiative) for renaissance from radiation } \\
\text { disaster }\end{array}$ \\
\hline & The University of Tokyo & Global Leadership initiative for an Age-Friendly Society \\
\hline & Ochanomizu University & $\begin{array}{l}\text { Fostering long-term creativity and innovation with science and technology disciplines } \\
\text { based on Ochanomizu spirit “Migakazuba” in the next generation of global leaders }\end{array}$ \\
\hline & Nagoya University & Leadership development program for space exploration and research \\
\hline & Waseda University & Leading graduate program in science and engineering \\
\hline \multicolumn{3}{|l|}{ Only-one category } \\
\hline & Hokkaido University & Fostering global leaders in veterinary science for contributing to one health \\
\hline & Gunma University & Program for cultivating global leaders in heavy ion therapeutics and engineering \\
\hline & Tokyo Institute of Technology & Global human resource development program for nuclear safety and security \\
\hline & University of Yamanashi & Green energy conversion science and technology \\
\hline & Nagoya University & The program for cross-border legal institution design \\
\hline & University of Hyogo & Next generation picobiology pioneered by photon sciences \\
\hline & Akita University & New frontier leader program for rare-metals and resources \\
\hline & $\begin{array}{l}\text { National Graduate Institute for } \\
\text { Policy Studies }\end{array}$ & GRIPS Global Governance Program \\
\hline & Shinshu University & Global leader program for fiber renaissance \\
\hline & $\begin{array}{l}\text { Shiga University of Medical } \\
\text { Science }\end{array}$ & $\begin{array}{l}\text { Reducing the burden of non-communicable disease (NCD) in the } \\
\text { Asian Pacific region }\end{array}$ \\
\hline & Kyoto University & Leading graduate program in primatology and wildlife science \\
\hline & Yamagata University & Graduate school of science and engineering \\
\hline & Chiba university & $\begin{array}{l}\text { Nurture of creative research leaders in immune system regulation and } \\
\text { innovative therapeutics }\end{array}$ \\
\hline & The University of Tokyo & Leading graduate course for frontiers of mathematical sciences and physics \\
\hline & Nagasaki University & $\begin{array}{l}\text { Program for nurturing global leaders in tropical and emerging } \\
\text { communicable diseases }\end{array}$ \\
\hline
\end{tabular}




\section{The Necessity of Strengthening Leadership Education}

Representatives of industry, especially in Japan, have indicated that more employees are needed that are well educated in leadership in order to compete successfully in global markets. The conventional wisdom regarding leadership has been that leadership stems primarily from authority, higher position, and a charismatic personality. However, during the last two decades, industry and the general public have called for new models of leadership without these features, namely, peer leadership, of which the most distinctive feature is that the skill of leadership can be mastered with training that is not derived from inborn personality and the environment [7,8]. Individuals with peer leadership skills are always prepared to face difficulties with the understanding that their mission is to resolve issues by offering constructive suggestions or cooperating with others. The following is a list of primary skills that Japanese industry (Keidanren) expects of new employees [9].

- Ability to tackle challenges

- Expertise/skills to take charge of tasks

- Problem solving ability

- Sense of responsibility

- Understanding various cultures and values

- Communication skills

Therefore, MEXT decided to start the LP to foster competent PhD students with deep specialization and peer leadership for the sustainable development of Japan.

\section{Create New Evaluation Criteria of Leadership Education: A Case of University of Hyogo}

\subsection{Outline}

The University of Hyogo established a new department, Department of Picobiology, in April 2013 to implement the LP entitled "Next Generation Picobiology: Focused on Photon Sciences". This 5-year PhD program offers students a monthly scholarship of JPY 200,000 to support their studies and research. This program comprises a combination of the most advanced sciences, liberal arts, and leadership education. It also allows students to access some of the world's most advanced analytical equipment, such as Raman spectrophotometers, Super Photon Ring $8 \mathrm{GeV}$ (SPring-8, a third-generation synchrotron radiation facility, RIKEN), neutron diffractors (J-PARC, JAEA), X-ray-free electron lasers (SACLA, RIKEN), electron microscopes, and a K computer (Fujitsu supercomputer with a Linuxbased operating system, RIKEN). Through cooperation with the RIKEN SPring-8 Center, students have the flexibility to discover issues that interest them along with the challenge of creatively developing new insights through the rigors of sciences that have been developed for this program. Students work closely with world-class researchers that are recruited for the program and benefit from many opportunities to foster their technical, analytical, and expressive abilities, as well as the IT, language, and problem-solving skills that are essential for future global leaders (Figure 2). 


\begin{tabular}{|l|}
\multicolumn{1}{|c|}{ Basic Subjects } \\
\hline Mathematics in Picobiology \\
Chemistry in Picobiology \\
Physics in Picobiology
\end{tabular}

\begin{tabular}{|l|}
\multicolumn{2}{|c|}{ Specialized Basic Subjects } \\
Introduction to Picobiology \\
Basic \& Technical Course Structural Analysis I-VI \\
I: SPring-8 \\
- II: SACLA \\
- III: Vibrational Spectroscopy \\
- IV: Electron Microscopy \\
V: Computer \\
Basic Structural Biology \\
Basic Cell Biology \\
Basic Study of High-resolution Structure \\
Laboratory Rotation \\
Research Exercise
\end{tabular}

Common Subjects

Advanced Course of Global Leadership Advanced Course of Career Paths for Ph.D. Philosophy of Science Bioethics

Science Communication Science Policy Internship

\section{Specialized Subjects}

Advanced Structural Biology
Advanced Cell Biology
Advanced Study of High-resolution Structure
Applied Life Science
Advanced Experiments in Picobiology
Exercise in Picobiology
Seminar and Thesis
Individual Exercise in Picobiology
Study Abroad

Figure 2. Various subjects for the Leading Program (LP) at University of Hyogo.

\subsection{Quality Assurance and Industry University Collaboration System}

Quality assurance is defined as a mechanism through which higher education institutions secure the quality of their educational and research offerings to build stakeholder confidence. Such approaches will include achieving intended outcomes and fulfilling stakeholder needs, as well as conforming to evaluation standards and the basic requirements stipulated by law [10-12].

The University of Hyogo has invited supporters (stakeholders) from not only life science corporations but also publishers, news agencies, and journalists to implement the LP. Many active leaders in industry have been invited as lecturers for common subjects such as Advanced Course of Global Leadership and Advanced Course of Career Paths for PhD. Students participate in internship programs provided by corporate stakeholders for one to three months. This industrial-academic collaboration has worked very well, since guest speakers bring real issues and challenges to the table that they have actually experienced [6]. This increases interest and a desire to learn among students because they are not dealing with fictional issues invented by academics.

Corporate sponsors also benefit from this collaboration system: students, as their future consumers, can offer them ideas for their products; sponsors can learn about the actual conditions under which the students learn and live, data that are useful for designing training plans for new employees; and they can educate employees using the collaboration system. However, new corporate sponsors are truly difficult to attract when only university staff are involved and other marketing ideas are needed to sustain this collaboration.

In Japan, it can be said that the recruitment process of new employees seems to prioritize academic clique over applicants' ability, and $\mathrm{PhD}$ students have much more difficulty in finding suitable jobs according to their background than Bachelors. Therefore, such collaboration activities may change the recruitment system of PhD students in the Japanese industry and government in the future. 


\subsection{Create New Evaluation Criteria of Required Leadership and Science Education}

The University of Hyogo is now trying to create new evaluation criteria of required leadership and science education in their LP from three standpoints: (1) growth of student as a scientist; (2) growth of student as a global leader; and (3) trends and needs in society. It is a noteworthy fact that they are creating the criteria in collaboration with their corporate sponsors. They recognize that past failure in leadership education, especially in Japan, has been caused by the mismatch between the expectations held by universities and industry: attaching too much emphasis to academic studies and lacking technical, human, and conceptual skills. This is why they decided to create new evaluation criteria with their corporate sponsors.

Graduates with leadership skills are unique and varied according to their specialized background. Therefore, human resources must be developed carefully considering such diverse types of individuals. On the other hand, they also have to produce $\mathrm{PhDs}$ who intently meet standards as global leaders. To solve these problems, it is effective to create new evaluation criteria that meet the expectations of leadership according to many stakeholders. If their evaluation criteria can be considered as an agreed standard of human resources shared with industry and all universities, their LP will be praised for generations to come.

\section{Concluding Remarks}

Peer leadership does not require authority, high position, or a charismatic personality; rather, it is a skill that can be acquired by training. LP designed by MEXT is fostering competent PhD students to become global leaders with deep specialization and peer leadership.

The University of Hyogo is implementing the program to foster global leaders with excellence in science by providing access to the world's most advanced analytical equipment through cooperation with the RIKEN SPring-8 Center. This is a completely innovative education program to foster PhDs with both knowledge of cutting-edge science and peer leadership. They are now trying to create new evaluation criteria of required leadership and science education in their LP with their corporate sponsors from three standpoints: growth of student as a scientist, growth of student as a global leader, and trends and needs in society.

The success of these special programs depends on not only how many graduates can play an active part in their future, but also how university staff can create a superior new evaluation criteria of human resource development and how much it can be shared with universities and industry. Additionally, this is directly linked to the success of global academic, industrial, and governmental sectors. However, the development of graduates and employees with a high level of special abilities takes time. Therefore, the LP should be stable and continued over the long term.

\section{Author Contributions}

Maya Okamoto conceived and designed the study. Hiroshi Matsuzaka provide valuable help on the educational administration system. Maya Okamoto and Hiroshi Matsuzaka co-wrote the paper. Both authors discussed the results and commented on the manuscript. 


\section{Conflicts of Interest}

The authors declare no conflict of interest.

\section{References}

1. Bennett, L. A framework for engaging leadership in higher education quality systems. In Leadership and Management of Quality in Higher Education; Nair, C., Webster, L., Mertova, P., Eds.; Elsevier: Amsterdam, Netherlands, 2010; pp. 55-71.

2. Bosch, H.; Teelken, C. Organisation and leadership in higher education. Learning from experiences in the Netherlands. High. Educ. Policy 2000, 13, 379-397.

3. Shahtalebia, S.; Yarmohammadianb, M.H.; Ajamic, S. Women's success factors from leadership in higher education. Procedia Soc. Behav. Sci. 2011, 15, 3644-3647.

4. White, K. Women \& leadership in higher education in Australia. Tert. Educ. Manag. 2003, 9, 45-60.

5. Japan Society for the Promotion of Science. Program for Leading Graduate Schools. In JSPS Annual Report 2012-2013; JSPS: Tokyo, Japan, 2013; pp. 48-49.

6. US IGERT: Integrative Graduate Education and Research Traineeship. Available online: http://www.igert.org/ (accessed on 5 January 2015).

7. Jenkinson, K.; Naughton, G.; Benson, A. The GLAMA (Girls! Lead! Achieve! Mentor! Activate!) and BLAST (Boys! Lead! Activate! Succeed Together!) peer leadership and physical activity program: A stealth intervention. J. Sci. Med. Sport. 2012, 15 (Suppl. 1), S116.

8. Mozhgana, A.; Parivashb, J.; Nadergholic, G.; Jowkard, B. Student leadership competencies development. Procedia Soc. Behav. Sci. 2011, 15, 1616-1620.

9. Keidanren Report 2011: Images of human resources sought in industry and expectations for university education (written in Japanese). Available online: https://www.keidanren.or.jp/ japanese/policy/2011/005/ (accessed on 5 January 2015).

10. Dill, D. Quality Assurance in Higher Education-Practices and Issues. In International Encyclopedia of Education, 3rd ed.; Elsevier: Amsterdam, Netherlands, 2010; pp. 377-383.

11. Van Vught, F.A.; Westerheijden, D.F. Quality Management and Quality Assurance in European Higher Education: Methods and Mechanisms; Office for Official Publications of the Commission of the European Communities: Luxembourg, Luxembourg, 1993.

12. European Science Foundation. Available online: http://www.esf.org/home.html (accessed on 5 January 2015).

(C) 2015 by the authors; licensee MDPI, Basel, Switzerland. This article is an open access article distributed under the terms and conditions of the Creative Commons Attribution license (http://creativecommons.org/licenses/by/4.0/). 